\title{
Predictors of relapse in the second follow-up year post cognitive-behavior therapy for panic disorder
}

\section{Preditores de recaída no segundo ano após terapia cognitivo- comportamental para pacientes com transtorno de pânico}

\author{
Elizeth Heldt, ${ }^{1,2}$ Letícia Kipper, ${ }^{2}$ Carolina Blaya, ${ }^{2}$ Giovanni A. Salum, ${ }^{2}$ Vânia N. Hirakata, ${ }^{2}$ Michael W. Otto, ${ }^{3}$ \\ Gisele G. Manfro ${ }^{1,2}$ \\ ${ }^{1}$ Anxiety Disorders Program, Hospital de Clínicas de Porto Alegre, (HCPA), Porto Alegre, RS, Brazil \\ 2 Postgraduate Program in Medical Sciences: Psychiatry, Universidade Federal do Rio Grande do Sul (UFRGS), Porto Alegre, RS, Brazil \\ ${ }^{3}$ Center for Anxiety-Related Disorders, Boston University, MA, USA
}

\begin{abstract}
Objective: To investigate predictors of relapse two years after a brief cognitive-behavior group therapy in patients with panic disorder who had failed to respond to pharmacologic treatment. Method: A total of 56 patients with panic disorder who had met remission criteria at 1 year evaluation after 12 sessions of cognitive-behavior group therapy were followed. Demographic and clinical features and life stressors were investigated as predictors of relapse. Results: At the 2 year assessment, 39 (70\%) patients maintained remission status and use of medication was reduced significantly, such that 36 (64\%) patients were not undergoing any psychiatric treatment. Among all independent variables investigated, only "conflict" as a stressful life event, $\mathrm{RR}=3.20\left(\mathrm{CI}_{95 \%} 1.60 ; 7.20-\mathrm{p}\right.$ $=0.001)$, and the severity or residual anxiety symptoms, $R R=3.60$ for each scale point $\left(\mathrm{CI}_{95 \%} 1.02 ; 1.08-\mathrm{p}<0.001\right)$, emerged as nonredundant predictors. Conclusion: In spite of the high treatment gains across two years of follow-up, clinicians should pay attention to stress management and to the role of residual symptoms during this period. Results were discussed in the context of treatment cost-efficacy and potential strategies to prolong treatment gains from cognitive-behavior group therapy.
\end{abstract}

Descriptors: Panic disorder; Cognitive therapy; Relapse; Follow-up studies; Stressful events

\section{Resumo}

Objetivo: Investigar os preditores de recaída após dois anos de terapia cognitivo-comportamental em grupo breve para pacientes com transtorno do pânico que não responderam ao tratamento farmacológico. Método: Um total de 56 pacientes com transtorno do pânico que preencheram os critérios de remissão em um ano de avaliação após as 12 sessões da terapia cognitivo-comportamental em grupo foram acompanhados. As caracteristicas demográficas, clinicas e os estressores de vida foram investigados como preditores de recaída. Resultados: No segundo ano de avaliação, 39 (70\%) pacientes mantiveram-se em remissão e o uso de medicação reduziu significativamente, de tal forma que 36 (64\%) pacientes não estavam em tratamento psiquiátrico. Entre todas as variáveis independentes investigadas, somente o "conflito" como evento estressor de vida, $R R=3,20\left(C I_{95 \%} 1,60 ; 7,20-p=0,001\right)$ e a gravidade ou os sintomas residuais de ansiedade, $R R=3,60$ para cada ponto a mais da escala $\left(C_{95 \%} 1,02 ; 1,08-p<0,001\right)$, foram preditores de recaida. Conclusão: A despeito dos ganhos do tratamento através dos dois anos, os terapeutas devem manter-se atentos em relação ao manejo do estresse e no papel dos sintomas residuais de ansiedade durante este periodo. Os resultados são discutidos no contexto de custo-eficácia do tratamento e nas potenciais estratégias para prolongar os ganhos da terapia cognitivo-comportamental em grupo.

Descritores: Transtorno de pânico; Terapia comportamental cognitiva; Recaida; Seguimento; Eventos estressores

\section{Introduction}

Panic disorder (PD) is a chronic and recurrent condition with lifetime prevalence rates of approximately 3.5\%. ${ }^{1}$ It impairs patients' quality of life and psychosocial functioning. ${ }^{2}$ Katschnig and Amering (1998) followed PD patients after a clinical drug trial and in the fourth year of evaluation they found that $31 \%$ of the patients were considered remitted, $45 \%$ not-remitted and

\section{Correspondence}

Elizeth Heldt

Psychiatry Service - Hospital de Clinicas de Porto Alegre, Universidade Federal do Rio Grande do Sul.

Rua Ramiro Barcelos, 2350 - Room 400N

90035-903 Porto Alegre, RS, Brazil

Phone: (+55 51) 3359-8294 Fax: (+55 51) 3359-8573

Email: eliz.h@globo.com 
$24 \%$ followed a pattern of remissions and relapses. ${ }^{3}$ The efficacy of pharmacological and cognitive-behavior therapy (CBT) for PD was examined in a meta-analytic study, and long-term outcome analysis suggested that cognitive-behavioral interventions were more successful than pharmacotherapy in maintaining treatment gains. ${ }^{4}$ As demonstrated by other studies, CBT has already been considered a good option for patients who want to discontinue the medication with persistent treatment gains. ${ }^{5,6}$

Across treatment outcome studies of PD, relatively few have focused on the prediction of relapse over longer term intervals. Brown and colleagues examined two year outcome in patients who had undergone 11 sessions of CBT. ${ }^{7}$ Despite maintenance of improvement for many patients, there was a waxing and waning of disorder severity over time. Significant predictors of poorer outcome at the 2-year assessment included pretreatment severity and use of medications, but notably did not include comorbidity. These minimal effects of comorbidity may stem from the degree to which CBT for PD also improves these comorbid conditions. ${ }^{8}$ Indeed, many of the documented negative effects of comorbidity on treatment outcome for $\mathrm{PD}$ are from unselected naturalistic ${ }^{9}$ or pharmacotherapy treatment studies, with evidence for minimal impact in CBT studies, particularly at follow-up assessments. ${ }^{10}$

A number of studies indicate a high prevalence of life stressors prior to the onset of PD as well as greater distress in response to these stressors. ${ }^{11-14}$ Moreover, a longitudinal study recently identified stress as a prospective predictor of first panic attacks among white collar workers. ${ }^{15}$ Less attention has been given to the role of stress in maintaining PD or leading to relapse. Life stress is associated with greater symptom severity in patients with $\mathrm{PD},{ }^{16}$ and in one study chronic stress was associated with poorer long term outcome from CBT for agoraphobia. ${ }^{17}$ Stress also appears to increase the probability of relapse after the discontinuation of serotonergic antidepressants ${ }^{18}$ and a great deal of evidence indicates that fear of anxiety symptoms plays a role in the etiology and maintenance of PD. ${ }^{19}$

The efficacy of CBT in group for PD has been described in previous studies, showing moderate to high effect size considering the different outcome measurements, after acute treatment ${ }^{20}$ and in one year follow-up. ${ }^{21}$ In the present study, we investigated predictors of relapse two years after a brief cognitive-behavior group therapy (CBGT) in patients who had failed to respond to pharmacologic treatment. In particular, we focused on providing additional data on the role of stressors in longer term outcome and also included the traditional predictors of symptom severity and comorbidity. By focusing only on patients who had completed treatment and done well in the initial 1-year post-treatment phase, we investigated those factors that may be most important for understanding the recurrence of PD in relatively stable patients.

\section{Method}

\section{Participants}

Participants from the Anxiety Disorder Outpatient Unit of Hospital de Clínicas de Porto Alegre (HCPA) received brief CBGT for PD during the period between 1998 and 2005. The study was approved by the Research Ethics Committee of HCPA ( $\mathrm{n}^{\circ}$ 07-231) and all patients provided written informed consent. ${ }^{20,21}$ All of them met criteria for PD with or without agoraphobia according to DSM-IV. To take part in the CBGT, patients had to have residual symptoms of PD such as panic attacks, anticipatory anxiety and phobic avoidance despite having been on a stable dose of medications for at least 4 months. The CGI (see below) severity score of three or greater was required for participation. Of the 98 patients who had participated in the treatment protocol, only 5 (5\%) were lost during follow-up. Ninty-three patients were interviewed at follow-up evaluations (between 2000 and 2007). The sample was characterized by $63(68 \%)$ women and $30(32 \%)$ men, with a mean (standard deviation) age of $38.8(\mathrm{SD}=10.3)$ years and a median (interquartile range) of 8.0 (3.0 to 13.0) years of PD duration.

In order to be selected for this 2-year study, patients also had to have achieved and maintained remission criteria by 1 -year post CBGT. In a previous study, some patients did not remit after acute treatment, yet remitted 1 year after CBGT, possibly because they needed more time for in vivo exposure. ${ }^{21}$ Those patients who did not remit in the first year $(\mathrm{n}=37 ; 40 \%)$ were excluded from this analysis. At the end, 56 (60\%) CBGT patients met selection criteria and were analyzed to factors associated with relapse across follow-up (Figure 1).

All 56 patients had been undergoing pharmacological treatment for PD when admitted to CBGT, with a median (interquartile range) duration of pharmacotherapy of 2.0(1.0 to 4.0) years and were considered "resistant to treatment" due to an inability or unwillingness to increase their medications' dose. ${ }^{22}$ Forty-three (77\%) patients were using serotonin selective reuptake inhibitors (SSRI) and $11(20 \%)$ tricyclic antidepressants (TCAs). Other drugs were used by 2 (4\%) patients (MAO inhibitors and lithium). Benzodiazepines were used in combination with antidepressants by $17(30 \%)$ patients, 2 patients (4\%) were on SSRI plus TCAs and only $1(2 \%)$ was on SSRI and lithium.

Among psychiatric comorbidities, 32 (57\%) met criteria for mood disorders (current and past major depression or dysthymia), and $19(34 \%)$ for other anxiety disorders (generalized anxiety disorder (GAD), social anxiety disorder or obsessive-compulsive disorder).

\section{Measures}

The Mini International Neuropsychiatry Interview (MINI) Brazilian version, ${ }^{23}$ a structured interview that provides standardized assessment of the main Axis I Psychiatric Disorders in accordance with the DMS-IV criteria, was applied by trained psychiatrists to confirm the PD diagnosis and establish comorbidity diagnoses. ${ }^{24}$ At study entry, a semi-structured interview was completed by the clinicians running the group to assess sociodemographic data and clinical history. Follow-up evaluations consisted of a face-to-face update of clinical state as assessed by the scales and questions regarding treatment status (medications, psychotherapy).

A structured interview to verify the occurrence of stressful life events in the last year was conducted by the same evaluator at the 


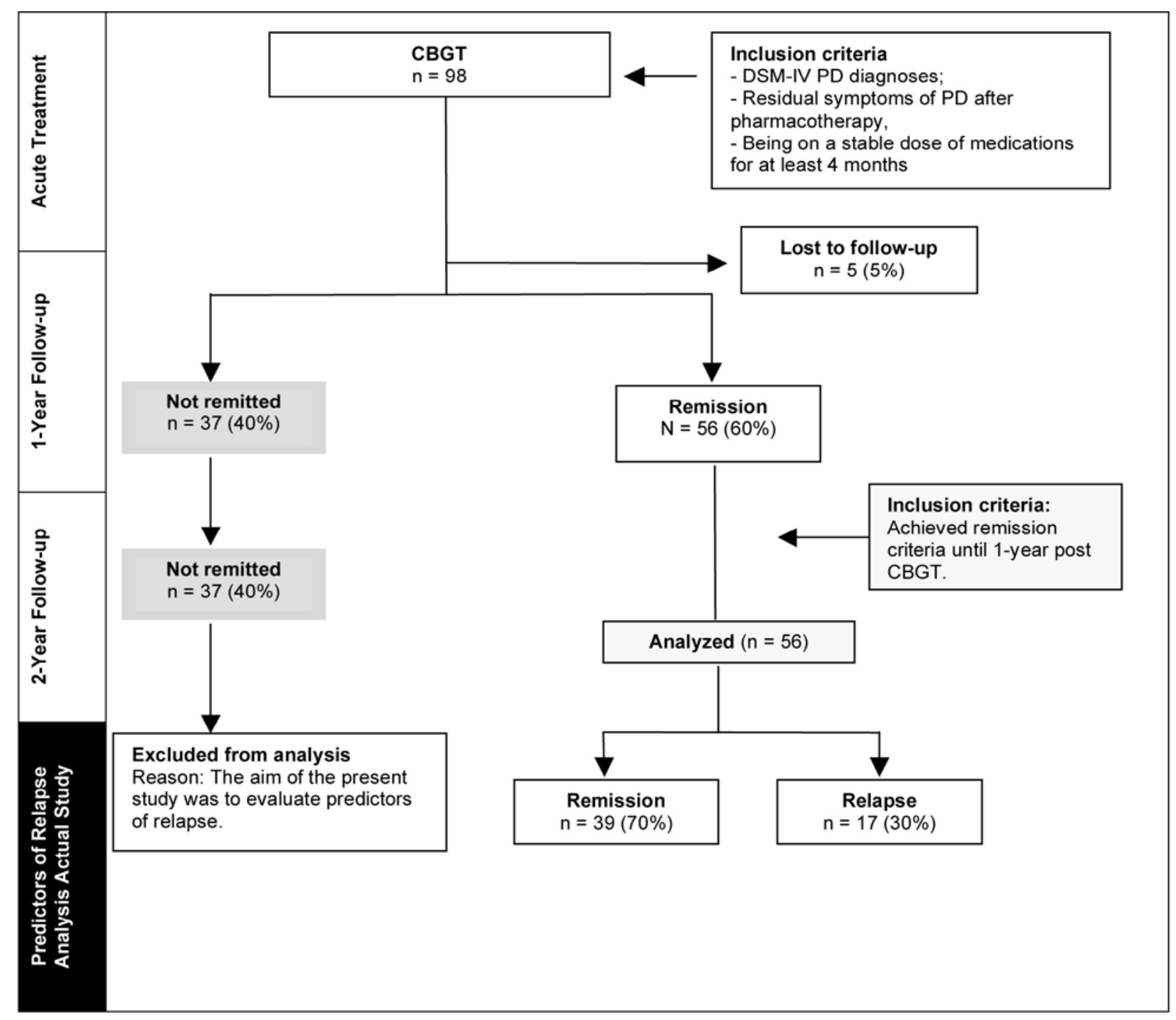

Figure 1 - Flow Diagram showing each stage of follow-up study and where these patients of the actual study came from Note: PD, Panic Disorder. CBGT, Cognitive-Behavior Group Therapy

2-year follow-up. The aim of this interview was to elicit further information about the context in which such events took place and to assess the precise meaning of and perceived threat posed by the stressors. These stressful events were categorized according to Manfro et al.:." "loss", for events including death of a loved one, divorce or moving to a new location; "conflict", if difficulties occurred in interpersonal relationships, or if there were occupational or financial problems; "medical illness" when patients reported the onset or exacerbation of a medical condition; "others" for all stressful events reported that could not be categorized into one of the above. ${ }^{12}$

The Clinical Global Impressions scale (CGI), ${ }^{25}$ the Panic Inventory (PI), ${ }^{20}$ and the Hamilton Rating Scale for Anxiety $(\mathrm{HAM}-\mathrm{A})^{26}$ were used to assess severity at baseline, after the $12^{\text {th }}$ weekly session and at 1 and 2 years post treatment using a 2-month period as the frame of reference for ratings. ${ }^{27}$ The CGI was used to provide a global rating of the severity of the illness (1 to 7 ) according to the frequency and intensity of panic attacks, anticipatory anxiety, phobic avoidance and familial or occupational functioning. The PI characterizes the frequency (spontaneous or situational, full or limited), the intensity (rated on a 0-10 scale) and the duration (minutes) of panic attacks. Agoraphobia and anticipatory anxiety severity were rated on a scale from 0 (none) to 10 . Outcome ratings at the end of the treatment and at follow up evaluations were completed by trained clinicians who had not participated in the group.

Consistent with previous studies, remission was defined by no panic attacks and CGI $\leq 2$ in the last 2 months of follow up, and relapse was considered when CGI $\leq 3$ or presence of panic attacks following a remission across the study. ${ }^{27}$

\section{Treatment}

The treatment protocol was an adaptation of the procedures manualized. ${ }^{28}$ The patients were treated in one of fourteen groups (with a mean of 7 patients per group) offering 12 treatment sessions over 4 months. The CBGT sessions have been described elsewhere. ${ }^{20,21}$ In brief, initial sessions were dedicated to providing a model of the disorder and treatment as well as introducing 
relaxation and diaphragmatic breathing skills and stepwise exposure to feared internal sensations (interoceptive exposure). Intermediate sessions were dedicated to continued interoceptive exposure as well as identification and correction of anxiogenic automatic thoughts. Final treatment sessions included stepwise in vivo exposure, as well as discussion and rehearsal of relapse prevention skills.

\section{Statistical analysis}

Data are presented as mean (standard deviation), median (interquartile range) and count (percent). Kolmogorov-smirnov test was used to evaluate normal distribution. Friedman test was used to assess changes in symptom severity across treatment and follow-up. Cochran's test was used to evaluate changes in medication intake throughout this study. For prediction of relapse at follow-up, difference within outcome groups as measured by the Fisher Exact test, Student t-test for independent samples and Mann-Whitney $\mathrm{U}$ for non-normal variables, with $\mathrm{p}$-value $<0.10$, was the criterion to enter a Poisson Regression. All tests were two-tailed. Statistical analysis was performed using the Statistical Package for the Social Sciences (SPSS) version 14.0. The selected significance level was $\alpha=0.05$ and the confidence level was $95 \%$.

\section{Results}

As summarized in Table 1, significant decreases in symptoms were evident for all outcome measures (frequency of panic attacks, agoraphobia and anticipatory anxiety) across group CBT, with maintenance of these gains at follow-up. Thirty-nine (70\%) patients remained in remission (no panic attacks and CGI $\leq 2$ ) at follow-up and 17 (30\%) of those who fulfilled remission criteria, relapsed between 1 and 2 years post CBT.

A total of 36 (64\%) patients were not undergoing any psychiatric treatment at the time of the 2-year follow-up evaluation: 31 (55\%) were in remission and $5(9 \%)$ had residual symptoms. Comparison of pharmacotherapy at baseline and at follow-up indicated a significant reduction in both antidepressants and benzodiazepines (BDZ). Fifty-five (98\%) patients were on antidepressants at baseline and $20(36 \%)$ discontinued the medication $(\mathrm{p}<0.001)$. Eighteen (32\%) were using BDZ on admission and only $7(12 \%)$ continued using them at the follow-up evaluation $(p<0.001)$. No association was found in the use of medication between patients who relapsed and those who remained in remission at the 2-year follow-up (Table 2).

\section{Predictors of relapse}

Demographic characteristics showed no significant association with relapse of PD. The mean age of the sample studied was 38.5 $(S D=10.3)$ years [remitted $39.1(S D=10.2)$, relapse $36.0(S D=$ 9.9); $\mathrm{t}=-1.038 ; \mathrm{df}=54 ; \mathrm{p}=0.304]$. No gender differences were found in the relapse group - 11 female (31\%) and 6 male (29\%), $\mathrm{p}_{\text {Fisher }}>0.999$. Forty patients $(71 \%)$ lived with a partner and the mean years of formal schooling was $11.5(\mathrm{SD}=3.9)$. Marital status ( without partner: remitted $=10(26 \%)$ and relapse $=6(35 \%)$; $\left.\mathrm{p}_{\text {Fisher }}=0.527\right)$ and years of study [remitted $=11.1(\mathrm{SD}=3.5)$ vs relapse $12.6(\mathrm{SD}=4.6) ; \mathrm{t}=1.316 ; \mathrm{df}=54 ; \mathrm{p}=0.194] \mathrm{did}$ not differ in the relapse and the remitted group.

We found no association between clinical features at baseline and the relapse of PD. We also examined whether severity of symptoms at the 1-year follow-up could be a predictor of relapse at the second year follow-up (Table 2). Agoraphobia, anticipatory anxiety, and anxiety symptoms evaluated by HAM-A were associated with relapse at the 2-year follow-up. However, since theoretically these measures probably have multicollinearity we decided to include only the HAM-A scale in the regression model.

Forty patients $(71 \%)$ reported the presence of stressful life events within the 1- and 2-year period of follow-up as shown in Table 3. Our results demonstrated that relapse in PD was associated with the specific stressful life events regarded as "conflict" $\left(\mathrm{p}_{\text {Fisher }}=0.004\right)$.

In order to identify whether stressful life events and severity of anxiety symptoms at 1-year follow-up offered prediction of relapse, we applied a Poisson multiple regression analysis. We found that both stressful life events and anxiety symptoms contribute to the prediction of PD disorder relapse. It was observed that patients who had reported stressful life events which they classified as 'conflict' with $\mathrm{RR}=3.20\left(\mathrm{CI}_{95 \%} 1.60\right.$; $7.20-p=0.001)$ and higher scores of severity of anxiety symptoms $\mathrm{RR}=3.60$ for each scale point $\left(\mathrm{CI}_{95 \%} 1.02 ; 1.08-\mathrm{p}\right.$ $<0.001)$ had higher relapse rates.

Table 1 - Symptom severity outcome measures across the study period $(n=56)$

\begin{tabular}{|c|c|c|c|c|c|c|}
\hline & \multirow[b]{2}{*}{ Baseline } & \multirow[b]{2}{*}{ 4-month } & \multirow[b]{2}{*}{ 1-Year } & \multirow[b]{2}{*}{ 2-Year } & \multicolumn{2}{|c|}{ Friedman test } \\
\hline & & & & & $\begin{array}{l}\text { Chi-Square } \\
\text { (df = 3) }\end{array}$ & p-value \\
\hline Panic attack & $1(0-15)$ & 0 & 0 & 0 & 50.653 & $<0.001$ \\
\hline Agoraphobia & $8(5.2-9.7)$ & $3(0-4)$ & $0(0-3)$ & $0(0-3)$ & 98.877 & $<0.001$ \\
\hline $\begin{array}{l}\text { Anticipatory } \\
\text { anxiety }\end{array}$ & $8(7-10)$ & $3(2-5)$ & $2(1-4)$ & $2(0-5)$ & 92.604 & $<0.001$ \\
\hline
\end{tabular}

CGI, Clinical Global Impressions; df, degree of freedom. Variables were presented by median (interquartile range). $p<0.05$ 
Table 2 - Clinical features as predictors of PD relapse post CBGT and the use of medications in the 2-year follow-up

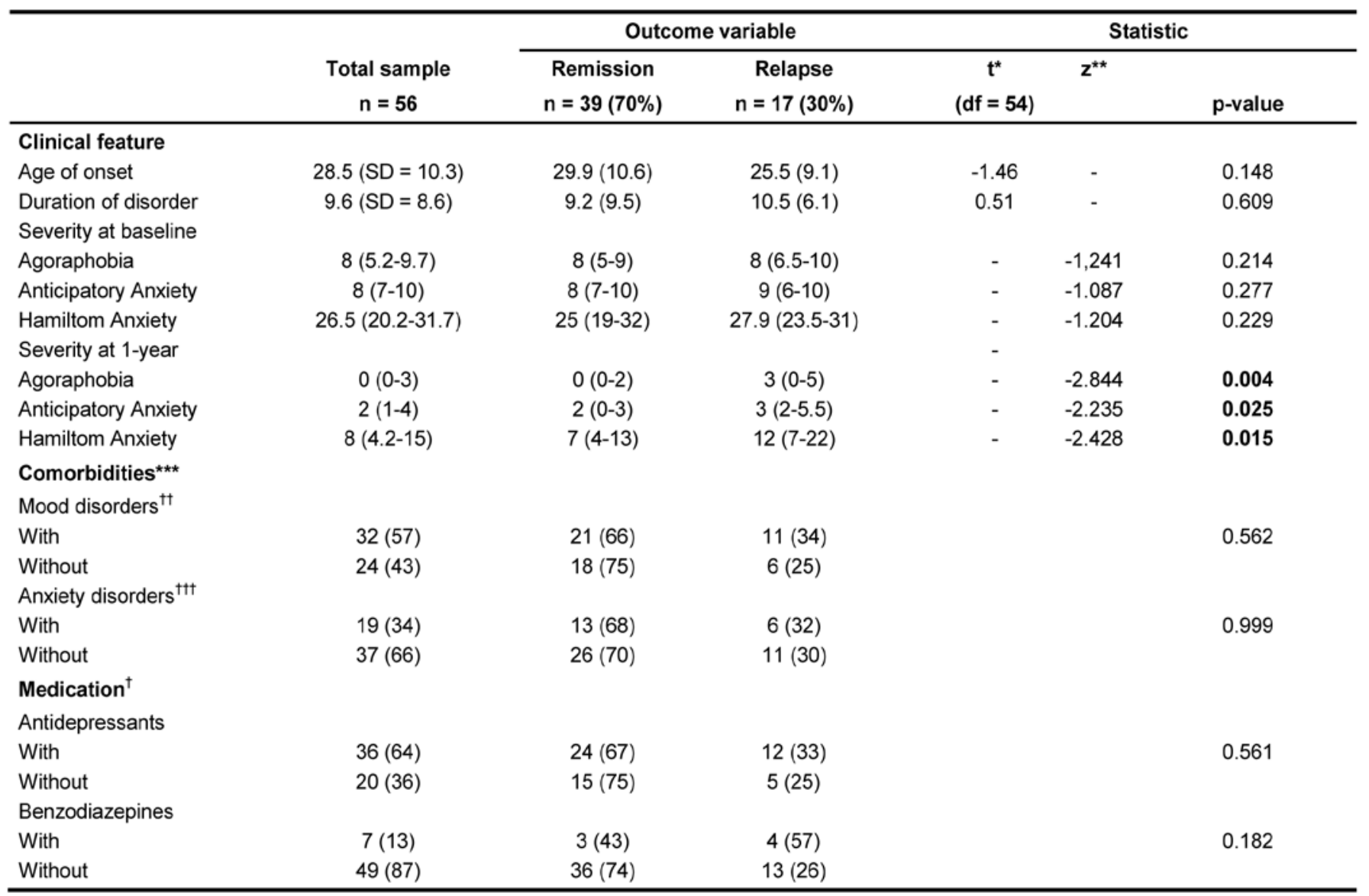

PD, Panic Disorder. CBGT, Cognitive-Behavior Group Therapy. SD, Standart deviation. df, degree of freedom. CGI, Clinical Global Impressions. Continuity variables were presented by mean $(S D)$ and median (interquartile range).

${ }^{\star}$ Normal distributed variables, Student $t$ test for independent samples was used. ${ }^{* *}$ Non-normal distributed variables, Mann-Whitney $U$ was used.

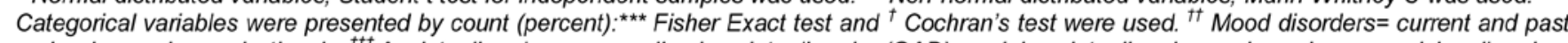
major depression or dysthymia. ${ }^{t t}$ Anxiety disorders= generalized anxiety disorder (GAD), social anxiety disorder or obsessive-compulsive disorder. $p<0.05$

\section{Discussion}

Rates of maintenance of treatment gains from brief, group CBT were high across two years of follow-up. Over twothirds of patients maintained their remission status during this evaluation period. Approximately one third of patients (30\%) did relapse between 1 and 2 years following treatment. It is noteworthy that initial levels of panic severity were not predictive. Likewise, although $57 \%$ of the sample $(n=32)$ had at least one comorbidity, this condition was not a predictor of PD relapse at follow-up, nor was disorder chronicity (mean 9.6 years). The absence of a strong relationship between pretreatment and longer-term clinical status is consistent with the notion that the course of PD was substantially changed by brief treatment, and that CBT in particular may be resilient to the negative effects of comorbity. ${ }^{10}$

Post-treatment measures of residual anxiety symptoms have been repeatedly shown to predict poor maintenance of treatment gains following acute treatment. ${ }^{7,29}$ Our study shows that the predictive role of residual symptoms is extended to long ( 2 year) outcomes. We also provided support for the role of stress in PD relapse, replicating early findings of a cost of stress on long-term outcome, ${ }^{17}$ and documenting that this effect is independent of the role of residual symptoms.

Accordingly, this study provides two findings of potential value to treating clinicians. Despite achieving longer-term remission at one year follow-up to brief treatment, clinicians should be careful to regard the role of residual symptoms; treatment of these symptoms at year one in booster sessions or other brief treatment format may have a role in ameliorating relapse rates. Also, attention to stress management (with either pre-training or booster sessions at that point) may help patients protect themselves from relapse when life stress strikes.

Our results are limited by the study's open naturalistic design. Also the absence of a control group limits us to attribute the remission and maintenance during follow-up to CBGT itself. The analyses are based on a small number of remitted individuals that could affect interpretation and external validity of the findings. Therefore, predictors with moderate to small effect size could not be detected due to lack of statistical power and only the major predictors could be properly evaluated. In addition, a standardized 
Table 3 - Psychosocial predictors of PD relapse post CBGT: 2-year follow-up

\begin{tabular}{lcccc}
\hline & & \multicolumn{2}{c}{ Outcome variable } & \\
\cline { 3 - 4 } $\begin{array}{l}\text { Stressful } \\
\text { life event }\end{array}$ & Total sample & Remission & Relapse & \\
& $\mathbf{n}=\mathbf{5 6}$ & $\begin{array}{c}\mathbf{n = 3 9} \\
\mathbf{( 7 0 \% )}\end{array}$ & $\begin{array}{c}\mathbf{n = 1 7} \\
\mathbf{( 3 0 \% )}\end{array}$ & p-value* \\
\hline Conflict & & & & \\
With & $17(30)$ & $7(41)$ & $10(59)$ & $\mathbf{0 . 0 0 4}$ \\
Without & $39(70)$ & $32(82)$ & $7(18)$ & \\
Loss & & & & \\
With & $6(11)$ & $5(83)$ & $1(17)$ & 0.655 \\
Without & $50(89)$ & $34(68)$ & $16(32)$ & \\
$\begin{array}{l}\text { Medical } \\
\text { illness }\end{array}$ & & & & \\
With & $7(13)$ & $4(57)$ & $3(43)$ & 0.662 \\
Without & $49(87)$ & $35(71)$ & $14(29)$ & \\
Others & & & & \\
With & $12(21)$ & $9(75)$ & $3(25)$ & 0.738 \\
Without & $44(79)$ & $30(68)$ & $14(32)$ & \\
\hline
\end{tabular}

Note: PD, Panic Disorder. CBGT, Cognitive-Behavior Group Therapy.

Categorical variables were presented by count (percent);

${ }^{\star}$ Fisher Exact test was used.

$p<0.05$

instrument to assess life events and measures that evaluated other vulnerability factors (i.e. anxiety sensitivity) was not used. However, the probability that the results are only due to non-specific factors is unlikely, given that our sample was drawn from a specific group of resistant patients that had been treated with medication for at least 4 months. Nonetheless, of the variables examined - demographic characteristics, baseline symptom severity and comorbidity, stressful life events, and severity at one-year follow-up - we identified when redundancy in prediction was statistically controlled, stressful life events and the severity or residual anxiety symptoms remained as significant predictors.

Cost efficacy analyses have shown an advantage for CBT relative to both pharmacotherapy and combined treatment in analyses of acute treatment and follow-up analyses. ${ }^{30}$ The advantage for CBT tends to grow over follow-up intervals as pharmacologic treatments continue to accrue treatment costs at a much higher rate. ${ }^{30,31}$ The current study further supports these findings. Patients had entered group CBT after failing to respond adequately to medications, and across treatment and one-year follow-up, use of medications was reduced significantly, such that $64 \%$ of patients were not undergoing any psychiatric treatment at the 2-year follow-up evaluation. Discontinuation of medications was not associated with relapse, consistent with previous studies of the use of CBT to aid medication discontinuation. ${ }^{32-35}$ During the one to two year follow-up period, the majority of patients continued to maintain their treatment gains. With clinical attention to the potential sources of relapse identified in the current study (i.e., residual symptoms and the management of life stress) there is the potential for expanding maintenance of treatment gains to an even larger proportion of patients treated with CBT. Further studies are necessary to replicate our findings, as well as to test new strategies to find out whether using different tools to teach patients how to deal with stressor life events could provide different outcomes.

\section{Disclosures}

\begin{tabular}{|c|c|c|c|c|c|c|c|}
\hline $\begin{array}{l}\text { Writting group } \\
\text { member }\end{array}$ & Employment & $\begin{array}{c}\text { Research } \\
\text { grant }^{1}\end{array}$ & $\begin{array}{c}\text { Other research grant } \\
\text { or medical continuous } \\
\text { education }\end{array}$ & $\begin{array}{l}\text { Speaker's } \\
\text { honoraria }\end{array}$ & $\begin{array}{c}\text { Ownership } \\
\text { interest }\end{array}$ & $\begin{array}{l}\text { Consultant/ } \\
\text { Advisory } \\
\text { board }\end{array}$ & Other $^{3}$ \\
\hline Elizeth Heldt & UFRGS & FIPE/HCPA* & - & - & - & - & - \\
\hline Leticia Kipper & UFRGS & FIPE/HCPA ${ }^{*}$ & - & - & - & - & - \\
\hline Carolina Blaya & UFRGS & FIPE/HCPA* & $\mathrm{CNPq}$ & Eli-Lilly* & - & - & - \\
\hline $\begin{array}{l}\text { Vânia N. } \\
\text { Hirakata }\end{array}$ & $\mathrm{HCPA}$ & - & - & - & - & - & - \\
\hline Michael W. Otto & Boston University & - & - & - & - & Organon* & - \\
\hline $\begin{array}{l}\text { Gisele Gus } \\
\text { Manfro }\end{array}$ & HCPA/UFRGS & FIPE/HCPA* & - & $\begin{array}{c}\text { Eli-Lilly* } \\
\text { Boehringer* }\end{array}$ & - & - & Roche* \\
\hline
\end{tabular}


References

1. Kessler RC, Chiu WT, Jin R, Ruscio AM, Shear K, Walters EE. The epidemiology of panic attacks, panic disorder, and agoraphobia in the National Comorbidity Survey Replication. Arch Gen Psychiatry. 2006;63(4):415-24.

2. Mendlowicz MV, Stein MB. Quality of life in individuals with anxiety disorders. Am J Psychiatry. 2000;157(5):669-82.

3. Katschnig H, Amering M. The long-term course of panic disorder and its predictors. J Clin Psychopharmacol. 1998;18(6 Suppl 2):6s-11s.

4. Gould RA, Otto MW, Pollack MH. A meta-analysis of treatment outcome for panic disorder. Clin Psychol Rev. 1995;15:819-44.

5. Barlow DH, Gorman JM, Shear MK, Woods SW. Cognitive-behavioral therapy, imipramine, or their combination for panic disorder: A randomized controlled trial. JAMA. 2000;283(19):2529-36.

6. Biondi M, Picardi A. Increase probability of remaining in remission from panic disorder with agoraphobia after drug treatment in patients who received concurrent cognitive-behavioral therapy: a follow-up study. Psychother Psychosom. 2003;72(1):34-42.

7. Brown TA, Barlow DH. Long-term outcome in cognitive-behavior treatment of panic disorder: clinical predictors and alternative strategies for assessment. J Consult Clin Psychol. 1995;63(5):754-65.

8. Tsao JC, Mystkowski JL, Zucker BG, Craske MG. Impact of cognitive-behavioral therapy for panic disorder on comorbidity: a controlled investigation. Behav Res Ther. 2005;43(7):959-70.

9. Bruce SE, Yonkers KA, Otto MW, Eisen JL, Weisberg RB, Pagano M, Shea MT, Keller MB. Influence of psychiatric comorbidity on recovery and recurrence in generalized anxiety disorder, social phobia, and panic disorder: a 12-year prospective study. Am J Psychiatry. 2005;162(6):1179-87.

10. Mennin DS, Heimberg RG. The impact of comorbid mood and personality disorders in the cognitive-behavioral treatment of panic disorder. Clin Psychol Rev. 2000;20(3):339-57.

11. Faravelli C, Pallanti S. Recent life events and panic disorder. Am J Psychiatry. 1989;146(5):622-6.

12. Manfro GG, Otto MW, Mcardle ET, Worthing JJ 3rd, Rosenbaum JF, Pollack MH. Relationship of antecedent stressful life events to childhood and family history of anxiety and the course of panic disorder. J Affect Disord. 1996;41(2):135-9.

13. Rapee RM, Litwin EM, Barlow DH. Impact of life events on subjects with panic disorder and on comparison subjects. Am J Psychiatry. 1990;147(5):640-4.

14. Roy-Byrne PP, Geraci M, Uhde TW. Life events and the onset of panic disorder. Am J Psychiatry. 1986;143(11):1424-7.

15. Watanabe A, Nakao K, Tokuyama M, Takeda M. Prediction first episode of panic attack among white-collar workers. Psychiatry Clin Neurosci. 2005;59(2):119-26.

16. Lteif NG, Mavissakalian MR. Life events and panic disorder/agoraphobia. Compr Psychiatry. 1995;36(2):118-22.

17. Wade SL, Monroe SM, Michelson LK. Chronic life stress and treatment outcome in agoraphobia with panic attacks. Am J Psychiatry. 1993;150(10):1491-5.

18. Mavissakalian MR, Guo S. Early detection of relapse in panic disorder. Acta Psychiatr Scand. 2004;110(5):393-9.

19. McNally RJ. Anxiety sensitivity and panic disorder. Biol Psychiatry. 2002;52(10):938-46.

20. Heldt E, Manfro GG, Kipper L, Blaya C, Maltz S, Isolan L, Hirakata VN, Otto MW. Treating medication-resistant panic disorder: predictors and outcome of cognitive-behavior therapy in a Brazilian public hospital. Psychother Psychosom. 2003;72(1):43-8.

21. Heldt E, Gus Manfro G, Kipper L, Blaya C, Isolan L, Otto MW. One-year follow-up of pharmacotherapy-resistant patients with panic disorder treated with cognitive-behavior therapy: outcomes and predictors of remission. Behav Res Ther. 2006;44(5):657-65.

22. Pollack MH, Otto MW, Kaspi SP, Hammerness PG, Rosenbaum JF. Cognitivebehavior therapy for treatment-refractory panic disorder. J Clin Psychiatry. 1994;55(5):200-5.

23. Amorim P. Mini International Neuropsychiatric Interview (MINI): validation of a short structured diagnostic psychiatric interview. Rev Bras Psiquiatr. 2000;22(3):106-15.

24. Sheehan DV, Lecrubier Y, Harnett SK, Amorim P, Janavs J, Weiller E, Hergueta T, Baker R, Dunbar GC. The Mini International Neuropsychiatric
Interview (MINI): the development and validation of a structured diagnostic psychiatric interview for DSM-IV and ICD-10. J Clin Psychiatry. 1998;59(Suppl 20):22-33.

25. Guy W. Clinical Global Impressions CGI. In: ECDEU Assessment Manual for Psychopharmacology. Review Edition. Rockville, MD: National Institute of Mental Health; 1976. p.217-22.

26. Hamilton M. The assessment of anxiety states by rating. Br J Med Psychol. 1959;32(1):50-5.

27. Keller MB, Yonkers KA, Warshaw MG, Pratt LA, Gollan BA, Massion AO, White K, Swartz AR, Reich J, Lavori PW. Remission and relapse in subjects with panic disorder and panic with agoraphobia: a prospective short-interval naturalistic follow-up. J Nerv Ment Dis. 1994;182(5):2906.

28. Otto MW, Jones JC, Craske MG, Barlow DH. Stopping anxiety medication: panic control therapy for benzodiazepine discontinuation (therapist guide). Oxford: Oxford University Press; 1996.

29. Dow MG, Kenardy JA, Johnson DW, Newman MG, Taylor CB, Thompson A. Prognostic indices with brief and standard CBT for panic disorder: I. Predictors of outcome. Psychol Med. 2007;37(10):1493-502.

30. McHugh RK, Otto MW, Barlow DH, Gorman JM, Shear MK, Woods SW. Cost-efficacy of individual and combined treatments for panic disorder. J Consult Clin Psychol. 2007;68(7):1038-44.

31. Otto MW, Pollack MH, Maki KM. Empirically-supported treatment for panic disorder: costs, benefits, and stepped care. J Consult Clin Psychol. 2000;68(4):556-63.

32. Otto MW, Hong JJ, Safren SA. Benzodiazepine discontinuation difficulties in panic disorder: conceptual model and outcome for cognitive-behavior therapy. Curr Pharm Des. 2002;8(1):75-80.

33. Schmidt NB, Wollaway-Bickel K, Trakowski JH, Santiago HT, Vasey M. Antidepressant discontinuation in the context of cognitive behavioral treatment for panic disorder. Behav Res Ther. 2002;40(1):67-73.

34. Whittal ML, Otto MW, Hong JJ. Cognitive-behavior therapy for discontinuation of SSRI treatment of panic disorder: a case series. Behav Res Ther. 2001;39(8):939-45.

35. Manfro GG, Heldt E, Cordioli AV, Otto MW. Cognitive-behavioral therapy in panic disorder. Rev Bras Psiquiatr. 2008;30(Suppl 2):S81-7. 